\title{
Effect of Refining Processes on Magnitude and Nature of Fenitrothion and Pirimiphos-Methyl Residues in Maize Oil and Bioavailability of their Cake Residues on Rats*
}

\author{
M. Farghaly ${ }^{\mathrm{a}}$, H. Taha ${ }^{\mathrm{a}}$, S.M. Soliman ${ }^{\mathrm{a}}$, U. Fathy ${ }^{\mathrm{a}}$ and A.H. \\ Bedair $^{\mathbf{b}}$ \\ ${ }^{a}$ Department of Applied Organic Chemistry, National Research \\ Centre, and ${ }^{b}$ Department of Chemistry, Faculty of Science, Al-Azhar \\ University,Cairo, Egypt.
}

\begin{abstract}
W AIZE seeds obtained from ${ }^{14} \mathrm{C}$-fenitrothion or ${ }^{14} \mathrm{C}$-pirimiphos1 methyl treated maize plants contained about $0.12 \%$ and $0.16 \%$ of the originally applied radioactivity, respectively. The concentration of ${ }^{14} \mathrm{C}$-fenitrothion residues and ${ }^{14} \mathrm{C}$-pirimiphos-methyl residues in crude oil (hexane extract) ranged from 2.8-3.0 ppm, methanol solubles $2.3 \mathrm{ppm}$ and in seed cake 1.2-1.4 ppm. Commercial processing procedures led to a gradual decrease in the total amount of ${ }^{14} \mathrm{C}$-residues in oils with aged residues. The refined oil contained only about $13-19 \%$ of the radioactivity originally present. The deodorization and alkali treatment are the most effective steps as they removed over $50 \%$ of the residues. Chromatographic analysis of refined oil revealed the presence of fenitrothion, 3-methyl-4nitrophenol as main products beside smaller amounts of fenitrooxon and desmethyl fenitrothion. Whereas, pirimiphos-methyl and 2diethyl-2-amino-4-hydroxy-6-methylpyrimidine were detected as principal compounds together with minor amounts of 2-ethyl-amino4-hydroxy-6-methylpyrimidine and 2-amino-4-hydroxy-6-methylpyrimidine.
\end{abstract}

On feeding rats with the extracted seeds (cake) for three days, the bound residues were found to be considerably bioavailable. A substantial amount of administrated bound ${ }^{14} \mathrm{C}$-residues was eliminated via respiration $(50 \%)$ for ${ }^{14} \mathrm{C}$-fenitrothion and excreted urine $(47 \%)$ for ${ }^{14} \mathrm{C}$-pirimiphos-methyl. While feces contained only $10-12 \%$ and about $22-26 \%$ of the radioactive residues were distributed among various organs of experimental animals.

Keywords: ${ }^{14} \mathrm{C}$-Fenitrothion, ${ }^{14} \mathrm{C}$-Pirimiphos-methyl, Maize seed oil, Insecticide residues, Refining processes and Bioavailability.

Pesticides are used globally for the protection of food, fiber, human health and comfort. Food safety is an area of growing worldwide concern on account of its direct bearing on human health. The presence of harmful pesticide residues in food and seed oils has caused a great concern among the consumers ${ }^{(1)}$. Several

"This paper was extracted from the Ph.D. thesis submitted to Faculty of Science, AlAzhar University. 
investigations suggest that most organophosphorus pesticides in edible oils can be reduced considerably by chemical refining processes ${ }^{(2-6)}$.

Two main organophosphorus insecticides are recommended for use on maize namely fenitrothion and pirimiphos-methyl against aphids according to the guide lines of the Egyptian Ministry of Agriculture $(2007)^{(7)}$.

Fenitrothion [O, O-dimethyl-O-(3-methyl-4-nitrophenyl) phosph-orothioate, I] is marketed under the different trade names Sumithion, Novathion and Metathion. It is a broad-spectrum organophosphorus insecticide, non-systemic and non-persistent ${ }^{(8,9)}$ and moderately toxic to mammals ${ }^{(10,11)}$. It is also used in agriculture to control insects on rice, wheat, barley, soybeans, cereals, fruits, coffee $^{(9)}$ and as a grain protectant and it finds use in horticulture, forestry, domestic and as a residual spray in homes for malaria control and public health applications $^{(10,12)}$.

Pirimiphos-methyl (actellic) [O,O-dimethyl-O-(2-diethyl-amino-6-methylpyrimidine-4-yl)] is a fast-acting broad spectrum insecticide with both contact and fumigant action and is a more effective protectant than other organophosphorus insecticides $^{(13)}$. It possesses a low order mammalian toxicity ${ }^{(14)}$. It degrades slowly in stored grains under most storage condition ${ }^{(15)}$ and shows activity against a wide variety of insects including ants, aphids, beetles, caterpillars, cockroaches, fleas, flies, mites, mosquitoes, moths, and thrips ${ }^{(16)}$.

Maize (Zea mays L.) is an economic and popular plant in Egypt, which is grown in more than one season. It is a high source of carbohydrate and good quality oil for human food, livestock feed and raw material for industrial processing ${ }^{(17)}$. Recently, corn oil production increased markedly and is refined into high quality oil for the food industry such as sweetener and $\operatorname{starch}^{(18)}$.

The aim of the present work was to study the effect of simulated commercial processing procedures on the elimination of the insecticide and its residues from maize seed oil obtained from plants treated with ${ }^{14} \mathrm{C}$-fenitrothion and/or ${ }^{14} \mathrm{C}$ pirimiphos-methyl as well as the bioavailability to rat of their cake residues.

\section{Materials and Methods}

\section{Chemicals}

Synthesis of ${ }^{14}$ C-fenitrothion [I]

${ }^{14} \mathrm{C}$-Fenitrothion-labelled at carbon atom of methyl groups-was synthesized by a single vesseled reaction in our laboratory (Scheme 1). This method involved the condensation of 0.007 mole of ${ }^{14} \mathrm{C}$-methanol in toluene to 0.003 mole of thiophosphorylchloride in presence of triethylamine (0.006) mole and the mixture was stirred at $5-10^{\circ} \mathrm{C}$ for $30 \mathrm{~min}$, then filtering the product to remove the separated triethylamine hydrochloride and the filtrate was evaporated under vacuum. The obtained (O, O-dimethylthiophosphoryl chloride) in toluene was allowed to react with 0.003 mole of potassium salt of 3-methyl-4-nitrophenol while stirring for $30 \mathrm{~min}$ at room temperature. This mixture was then refluxed for $2-3 \mathrm{hr}$ at $60-80^{\circ} \mathrm{C}$

Egypt. J. Chem. 53, No. 6 (2010) 
cooled followed by addition of cold water and the organic layer was separated, dried over anhydrous sodium sulphate. Under reduced pressure the solvent was evaporated to give yellow-brown liquid (b.p $140-145^{\circ} \mathrm{C}, 0.1 \mathrm{~mm}$ ) yield $70-75 \%$ (Scheme 1). The product was purified by preparative thin layer chromatography (TLC) (Silica gel $60 \mathrm{~F}_{254}$ pre-coated plates $20 \times 20 \mathrm{~cm}$ layer thickness $0.5 \mathrm{~mm}$, Merck, Germany). The prepared ${ }^{14} \mathrm{C}$-fenitrothion had a specific activity 2.96 $\mathrm{MBq} / \mathrm{mg}$ and a radiometric purity $98 \%{ }^{(19)}$ (Scheme 1$)$.

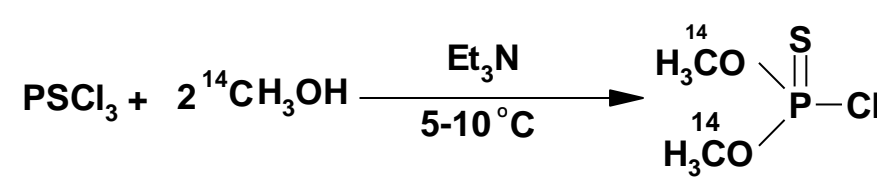<smiles>COP(=S)(O[14CH3])Oc1ccc([N+](=O)[O-])c(C)c1</smiles>

\section{${ }^{14} \mathrm{C}$-Fenitrothion [ I]}

Scheme 1. Synthesis of ${ }^{14} \mathrm{C}$-fenitrothion .

Pure fenitrothion (non-labelled) and its main degradation products were synthesized in our laboratory for comparison purposes ${ }^{(20-22)}$ (Fig 1).<smiles>COP(=S)(OC)Oc1ccc([N+](=O)[O-])c(C)c1</smiles>

Fenitrothion [l]<smiles>COP(O)(=S)Oc1ccc([N+](=O)[O-])c(C)c1</smiles>

Desmethylfenitrothion [III]<smiles>COP(=O)(OC)Oc1ccc([N+](=O)[O-])c(C)c1</smiles>

Fenitrooxon [II]<smiles>Cc1cc(O)ccc1[N+](=O)[O-]</smiles>

3-methyl-4-nitrophenol [IV]

Fig. 1. Fenitrothion and its main degradation products in maize seed oil . 
Synthesis of non-labelled pirimiphos-methyl

A mixture of 0.05 mole of 2-diethylamino-4-hydroxy-6-mehyl pyrimidine and 0.05 mole of anhydrous potassium carbonate in dry benzene was refluxed for $3 \mathrm{hr}$ and the obtained water was removed by azeotropic distillation. The resulting potassium salt was dissolved in $100 \mathrm{ml}$ of methyl ethyl ketone and stirred at $60^{\circ} \mathrm{C}$. O,O-Dimethyl chlorophosphorothioate $(0.06$ mole) was added dropwise to the pervious solution and the whole mixture was refluxed at $94-95^{\circ} \mathrm{C}$ for two hours to give 0.18 mole of pirimiphos-methyl as colourless liquid (b. $\mathrm{p}=128-132{ }^{\circ} \mathrm{C}, 0.04 \mathrm{~mm}$ ) yield $85-90 \%$, purity about $95 \%{ }^{(23)}$. Its main degradation products were synthesized in our laboratory $^{(24-26)}$ for comparison studies as shown in Scheme 2 and Fig. 2.

${ }^{14} \mathrm{C}$-Pirimiphos-methyl labelled at position 2 of the pyrimidine ring, was purchased from Izinta Isotope Trading Inerprise of the Institute of Isotopes, Budapest, Hungary. It had a specific activity $1.98 \mathrm{MBq} / \mathrm{mg}$. Radiometric purity was over $97 \%$.

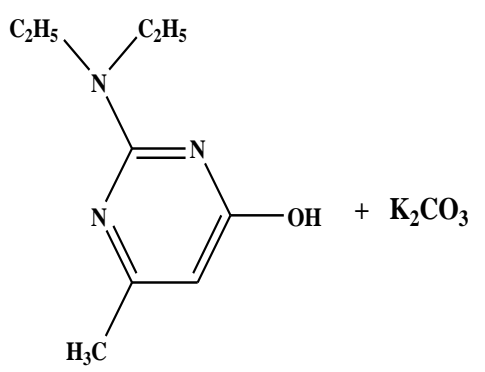

2-Diethylamino-4-hydroxy-6-methyl pyrimidine

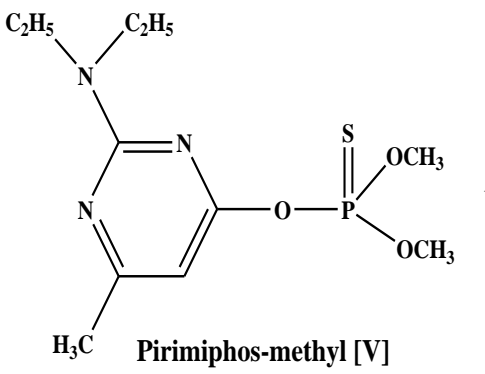

Scheme 2. Synthesis of non-labelled pirimiphos-methyl .

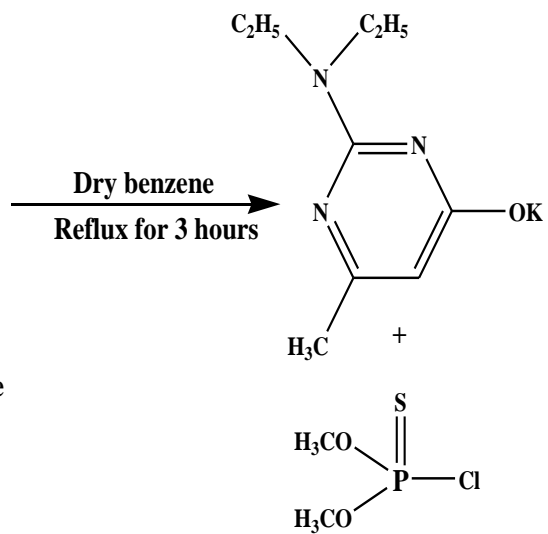

Dimethyl chlorothiophosphate

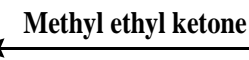

Reflux for 2 hours 
<smiles>CCN(CC)c1nc(C)cc(OP(=O)(OC)OC)n1</smiles>

Pirimiphos-methyl [V]<smiles>CCN(CC)c1nc(C)cc(O)n1</smiles>

2-Diethyl amino-4-hydroxy-6-methylpyrimidine [VI]<smiles>Cc1cc(O)nc(N)n1</smiles>

2-Ethyl amino-4-hydroxy-6-methylpyrimidine [VII]

2-Amino-4-hydroxy-6-methylpyrimidine [VIII]

Fig. $2 .{ }^{14} \mathrm{C}$-Pirimiphos-methyl and its main degradation products in maize seed oil.

Seeds

Pesticide-free Zea-mays seeds (Var. Giza.1 hybrid) were obtained from Agricultural Research Centre (Cairo). The seeds were cleaned from any dockage and impurities before cultivation.

\section{Field experiment}

Sound whole seeds of maize were cultivated in alluvial soil under normal field conditions in controlled and isolated field area (2 seasons). Irrigation, fertilization and soil management were carried out as practiced in the field according to the guide lines of the Egyptian Ministry of Agriculture (2007) ${ }^{(7)}$. Shortly before blooming stage, leaves of plants were treated twice, 23 days apart, with ${ }^{14} \mathrm{C}$-fenitrothion or ${ }^{14} \mathrm{C}$-pirimiphos-mehyl at a dose of $6 \mathrm{mg} / \mathrm{plant}$ which is equivalent to $0.8 \mu \mathrm{Ci}$ and $1.0 \mu \mathrm{Ci}$, respectively. At maturity, seeds were collected and dried for preparation of oil and cake.

\section{Extraction of the oil from seeds}

Maize seeds (400g) were crushed and soxhlet extracted with n-hexane for $6 \mathrm{hr}$ and the maize oil obtained after evaporation of hexane under reduced pressure. The remaining residues were further extracted with methanol for $6 \mathrm{hr}$ to isolate the polar ${ }^{14} \mathrm{C}$-residues ${ }^{(27)}$. Both extracts and cake were used for determination of their radioactivity.

\section{Simulated commercial processing procedures}

Removal of pesticide residues from oils was carried out through several refining processes . 
Alkali refining (Neutralization)

The crude oil sample (20 g) was stirred vigorously with $2 \mathrm{~N}$ sodium hydroxide solution for about $30 \mathrm{~min}$ at $27{ }^{\circ} \mathrm{C}$. The mixture was then centrifuged to remove the soap and excess alkali, washed several times with warm water until pH 7.0 and centrifuged at $3000 \mathrm{rpm}$ for $10 \mathrm{~min}$ to obtain the clear oil. This process removed free fatty acids and other acidic materials from oil.

\section{Bleaching}

The alkali refined oil (Neutralized oil) was treated with $0.5 \%$ (by weight) of a factory grade Fuller's earth (Tonsil), the mixture was stirred vigorously at 80 $100^{\circ} \mathrm{C}$ on an oil bath for $20 \mathrm{~min}$ and then centrifuged. The bleached oil was filtered.

\section{Winterization}

The clear dry oil was winterized at $5{ }^{\circ} \mathrm{C}$ for three days and the separated saturated glycerides were removed by centrifugation.

\section{Deodorization}

Deodorization is the last major processing step in the refining of edible oils and is responsible for removing undesirable ingredients. Superheated steam was passed into the heated winterized oil at about $200-220^{\circ} \mathrm{C}$ under reduced pressure for three hours to remove steam distillable materials including odours.

Aliquots of oil, after each refining process, were analyzed for their radioactivity.

\section{Bioavailability of bound residues to rats}

Two adult male albino rats weighting 180-210 g were obtained from the Animal House at National Research Centre, Dokki, Cairo. The rats were placed individually in glass metabolism cages which allowed separation and collection of feces, urine and expired air. The rats were conditioned for 2 days to a daily standard diet, and then were left for $24 \mathrm{hr}$ without feed, after which they were fed a known amount of extracted maize seeds $(21 \mu \mathrm{g}$ pirimiphos-methyl/rat; $84 \mu \mathrm{g}$ fenitrothion/rat) for 3 days. To make the feed palatable, the extracted maize seeds were mixed thoroughly with an equal amount of white cheese and the paste was left to dry. The expired ${ }^{14} \mathrm{CO}_{2}$ was trapped in $10 \% \mathrm{NaOH}$ solution. Urine, feces and ${ }^{14} \mathrm{CO}_{2}$ were collected separately for 3 days, and assayed for their radioactivity. After $72 \mathrm{hr}$, each rat was lightly anaesthetized with ether and blood removed from the pumping heart. The rat was then sacrificed by decapitation and samples of selected organs such as liver, kidney, fat, blood and heart were analyzed for total radiocarbon by combustion in Harvey Biological Oxidizer (Model OX-600) and followed by Liquid Scintillation Counting (LSC).

Egypt. J. Chem. 53, No. 6 (2010) 
Isolation and characterization of radioactive residues

Samples of oil, after each refining process, were partitioned between acetonitrile and hexane to remove the oil. The radioactive residues were almost completely retained in the acetonitrile layer. Analysis of crude and refined oil extracts were achieved by thin layer chromatography (TLC). Urine was extracted with chloroform (chloroform I) and the aqueous layer was then acidified with $2 \mathrm{~N}$ $\mathrm{HCl}$ and heated for $2 \mathrm{hr}$ on a water bath and reextracted with chloroform (chloroform II) to obtain the conjugated metabolites, Aliquots from both chloroform I, II were analyzed by TLC on silica gel plates using suitable systems.

Thin Layer Chromatographic (TLC) analysis

Residues were characterized by TLC on silica gel plates $(20 \times 20 \mathrm{~cm} ; 0.25 \mathrm{~mm}$ thickness) with fluorescent indicator (Kiesel gel $60 \mathrm{~F}_{254}$, Merck, Germany) using suitable systems for fenitrothion and pirimiphos-methyl. Authentic samples were run alongside as references for identification and the plates were seen under UVlight at $254 \mathrm{~nm}$ and spots were made visible by spraying the plates with Vanillin/Sulphuric acid (2.5\%).

High Performance Liquid Chromatography analysis (HPLC)

Analysis by HPLC was afforded on a Helwet Packard (1100 U.S.A) equipped with gradient system pumping, solvent programmer, the stainless steel column $(125 \times 4 \mathrm{~mm}$ I.D) was packed with $5 \mu \mathrm{m}$ ODS-Hypersil, variable-wavelength UV detector operated at $254 \mathrm{~nm}$. The mobile phase consisted of a mixture of acetonitrile: water (1:1 by volume).

\section{Radiometric measurements}

Radioactivity in oil (acetonitrile extracts), methanol extracts, urine and other liquid samples were measured directly by LSC (Packard Model RI-CARB 2300 $\mathrm{TR})$ in vials using a dioxane-based scintillation cocktail ${ }^{(28)}$.

Solid samples, ground maize seeds, cake, feces and animal tissues were assayed for radioactivity by combusting a definite weight $(100 \mathrm{mg})$ in a Harvey Biological Oxidizer (Model OX-600), followed by LSC. The internal standard $\left({ }^{14} \mathrm{C}\right.$ n-hexadecane $\left.0.2 \mu \mathrm{Ci} / \mathrm{ml}=74 \mathrm{KBq} / \mathrm{ml}\right)$ technique was used for quench correction. Thin layer plates were divided in $1 \mathrm{~cm}$ increments, scraped into vials, eluted with methanol, covered with scintillator and counted.

\section{Results and Discussion}

Field studies with aged residues

The persistent insecticides are beneficial for controlling pests for extended periods however their residues in consumable parts of the crops may be harmful to the consumers ${ }^{(29)}$.

${ }^{14}$ C-Residues in seeds, oil and cake

Under local agricultural conditions, the aged insecticide residues were detected at harvest in mature seeds after foliar application of the used organophosphorus insecticides. Maize seeds obtained from ${ }^{14} \mathrm{C}$-fenitrothion or ${ }^{14} \mathrm{C}$-pirimiphos-methyl treated maize plants contained about $0.12 \%$ and $0.16 \%$ of the originally applied radioactivity, respectively. Zayed et al. reported that, $0.37 \%$ and $0.11 \%$ of ${ }^{14} \mathrm{C}$-residues were detected in soybeans and cotton seeds 
which were obtained after spraying soybean plant with pirimiphos-methyl ${ }^{(30)}$ and cotton plant with malathion ${ }^{(27)}$ under similar conditions.

Table 1 shows that ${ }^{14} \mathrm{C}$-residues associated with crude oil (hexane extract) are $10-12 \%$ and those in methanolic extract $5-7 \%$ for pirimiphos-methyl and fenitrothion, respectively. While the ${ }^{14} \mathrm{C}$-residues in cake accounted for $63 \%$ of total residues of the two insecticides inside the seeds.

TABLE 1. Distribution of ${ }^{14} \mathrm{C}$-fenitrothion and ${ }^{14} \mathrm{C}$-pirimiphos-methyl residues in $100 \mathrm{~g}$ of maize seeds.

\begin{tabular}{|c|c|c|c|c|c|c|}
\hline \multirow{3}{*}{ Fractions } & \multicolumn{3}{|c|}{${ }^{14} \mathrm{C}$-fenitrothion } & \multicolumn{3}{|c|}{${ }^{14} \mathrm{C}$-pirimiphos-methyl } \\
\hline & \multirow{2}{*}{$\begin{array}{c}\text { Weight } \\
\text { (g) }\end{array}$} & \multicolumn{2}{|c|}{ Residues } & \multirow{2}{*}{$\begin{array}{c}\text { Weight } \\
\text { (g) }\end{array}$} & \multicolumn{2}{|c|}{ Residues } \\
\hline & & $(\mu \mathrm{g})$ & $\%$ & & $(\mu \mathrm{g})$ & $\%$ \\
\hline Maize seeds & 100 & $160 \pm 1.3$ & 100 & 100 & $180 \pm 1.7$ & 100 \\
\hline $\begin{array}{l}\text { Hexane extract } \\
\text { (oil) }\end{array}$ & 7 & $19.5 \pm 0.2$ & 12 & 6 & $18 \pm 0.6$ & 10 \\
\hline Methanol extract & 5 & $11.5 \pm 0.2$ & 7 & 4 & $9.0 \quad \pm 0.4$ & 5 \\
\hline Cake & 82 & $101 \pm 1.5$ & 63 & 85 & $117 \pm 1.0$ & 65 \\
\hline Recovery & 94 & 132 & 82 & 95 & 144 & 80 \\
\hline
\end{tabular}

Data are means of three replicates.

Total ${ }^{14} \mathrm{C}$-in seeds $=100 \%$.

\section{Effect of refining processes}

The effect of individual simulated commercial processing procedures on ${ }^{14} \mathrm{C}$ residues is shown in Table 2 . These processes led to a gradual decrease in the total amount of ${ }^{14} \mathrm{C}$-residues in oils with aged residues which are attributed to alkali hydrolysis, effect of adsorption, effect of heat and/or evolution of ${ }^{14} \mathrm{CO}_{2}$ gas. The deodorization process proved to be the most effective step in reducing of ${ }^{14} \mathrm{C}$-fenitrothion residues as it eliminated $31 \%$ of the residues originally present in crude oil, while the alkali treatment (neutralization), bleaching and winterization processes removed about $27 \%, 13 \%$ and $10 \%$ of these residues, respectively.

TABLE 2. Effect of commercial processing procedures on magnitude of ${ }^{14} \mathrm{C}$-insecticide residues in maize seeds oil.

\begin{tabular}{|c|c|c|c|c|}
\hline \multirow{3}{*}{ Treatment } & \multirow{2}{*}{\multicolumn{2}{|c|}{$\begin{array}{c}{ }^{14} \mathrm{C} \text {-fenitrothion } \\
{ }^{14} \mathrm{C} \text {-Residues in oil with aged } \\
\text { residues }\end{array}$}} & \multirow{2}{*}{\multicolumn{2}{|c|}{$\begin{array}{c}{ }^{14} \mathrm{C} \text {-pirimiphos-methyl } \\
{ }^{14} \mathrm{C} \text {-Residues in oil with aged } \\
\text { residues }\end{array}$}} \\
\hline & & & & \\
\hline & ppm & $\%$ Reduction & ppm & $\%$ Reduction \\
\hline Crude oil & $2.80 \pm 0.15$ & $\begin{array}{ll}----- \\
\end{array}$ & $3.00 \pm 0.11$ & $\begin{array}{ll}------ \\
\end{array}$ \\
\hline Alkali refining & $0.75 \pm 0.17$ & 27 & $0.78 \pm 0.10$ & 26 \\
\hline Bleaching & $0.36 \pm 0.10$ & 13 & $0.63 \pm 0.15$ & 21 \\
\hline Winterization & $0.28 \pm 0.20$ & 10 & $0.39 \pm 0.01$ & 13 \\
\hline Deodorization & $0.87 \pm 0.10$ & 31 & $0.81 \pm 0.02$ & 27 \\
\hline Total Reduction & - ------ & 81 & - ------- & 87 \\
\hline
\end{tabular}

$\mathrm{ppm}=\mu \mathrm{g}$ insecticide/gm oil

Data are means of three replicates.

Egypt. J. Chem. 53, No. 6 (2010) 
Both deodorization and neutralization processes seem to cause maximum reduction in the amount of ${ }^{14} \mathrm{C}$-pirimiphos-methyl residues, since they eliminated about $53 \%$, whereas the bleaching and winterization processes reduced $34 \%$ of the residues originally present in crude oil (Table 2). It is worthy to mention that, on refining soybeans oil which is contaminated with some organophosphorus insecticides such as malathion, dichlorvos and chlorpyrifos residues, deodorizing process is the most effective step in removing pesticide residues due to combination of decomposition and volatilization ${ }^{(31)}$. Recently, many authors also reported that, simazie residues in olive oil and prothiofos residues in canola oil are highly eliminated during deodorizing step $^{(32,33)}$.

The total refining processes reduced about $81-87 \%$ of the total ${ }^{14} \mathrm{C}$-residues as shown in Table 2. Zayed et al., ${ }^{(2,30)}$ showed that the amount of both ${ }^{14} \mathrm{C}$ carbofuran and ${ }^{14} \mathrm{C}$-pirimiphos-methyl residues in soybeans oil decreased to $16 \%$ and $25 \%$, respectively through the refining processes. It is also found that the complete refined sunflower oil obtained from treated sunflower plants lost about $64 \%$ of the total ${ }^{14} \mathrm{C}$-zineb residues in crude oil ${ }^{(34)}$ and $69 \%$ of ${ }^{14} \mathrm{C}$ prothiofos residues in canola oil ${ }^{(33)}$.

Identification and characterization of ${ }^{14} \mathrm{C}$-residues in crude and refined oil Chromatographic analysis (TLC and HPLC) of the crude oil in case of ${ }^{14} \mathrm{C}$ fenitrothion aged residues, shows mainly the presence of the parent compound fenitrothion [I] and three minor degradation products were identified as fenitrooxon [II], desmethyl fenitrothion [III] and 3-methyl-4-nitrophenol [IV]. $\mathrm{R}_{\mathrm{f}}$ and $R_{t}$ values of these metabolites are shown in Table 3. The amount of each minor compound did not exceed than $10 \%$ of the total residues. Generally, the residues in all steps of refined oil were identified as I and IV and traces amounts of II and III which were almost completely eliminated through oil processing (Table 3 \& Fig 1). Compound IV can be detected only by coloring reagent. The methanol extractable residues consisted of the hydrophilic compounds as free metabolites dimethyl phosphorothioate and dimethyl phosphate in addition to conjugated metabolites which upon hydrolysis with $2 \mathrm{~N} \mathrm{HCl}$ at $100{ }^{\circ} \mathrm{C}$ and then extraction with chloroform gave compounds III, IV. 
TABLE 3. $R_{f}, R_{t}$ values and percent of fenitrothion and its degradation products in maize oil after subjecting to different commercial processing procedures.

\begin{tabular}{|c|c|c|c|c|c|c|c|c|c|}
\hline \multirow{2}{*}{ Compound } & \multicolumn{3}{|c|}{$\mathbf{R}_{\mathbf{f}}$ values } & \multirow{2}{*}{$\begin{array}{c}\mathbf{R}_{\mathbf{t}} \\
\text { values }\end{array}$} & \multicolumn{5}{|c|}{ Relative percentage \% } \\
\hline & Sys. 1 & Sys. 2 & Sys. 3 & & $\mathbf{A}$ & B & $\mathrm{C}$ & D & $\mathbf{E}$ \\
\hline Fenitrothion $[\mathrm{I}]$ & 0.90 & 0.75 & 0.90 & 9.32 & 70 & 55 & 45 & 35 & 15 \\
\hline Fenitrooxon [II] & 0.82 & 0.44 & 0.74 & 2.47 & 10 & 5 & 3 & $\begin{array}{l}\text { Tra } \\
\text { ce }\end{array}$ & $\begin{array}{l}---- \\
-- \\
\end{array}$ \\
\hline $\begin{array}{l}\text { Desmethyl } \\
\text { fenitrothion[III] }\end{array}$ & 0.72 & 0.35 & 0.78 & 0.96 & 5 & 3 & 2 & ----- & --- \\
\hline $\begin{array}{l}\text { 3-methyl-4- } \\
\text { nitrophenol [IV] }\end{array}$ & 0.80 & 0.38 & 0.76 & 2.24 & \multicolumn{5}{|c|}{ Detected by color ${ }^{\mathrm{a}}$} \\
\hline
\end{tabular}

$\mathrm{A}=$ Crude oil, $\mathrm{B}=$ =Alkali refined oil, $\mathrm{C}=\mathrm{Bleached}$ oil, $\mathrm{D}=$ Winterized oil, $\mathrm{E}=$ Deodorized oil

System 1= Toluene: Ethyl acetate: Acetic acid (5:7:1)

System 2= Toluene: Acetic acid $(7: 1)$

System 3= Acetonitrile: Water: Ammonia (85:14:1)

$\mathrm{a}=$ Coloring reagent: Vanillin/sulphuric acid

The chromatographic analysis (TLC and HPLC) of the crude oil and refined oil are shown in Table 4. They contained pirimiphos-methyl [V] and 2-diethyl-2amino-4-hydroxy-6-methylpyrimidine [VI] as major degradation products, in addition to smaller amounts of 2-ethyl-2-amino-4-hydroxy-6-methylpyrimidine [VII] and 2-amino-4-hydroxy-6-methylpyrimidine [VIII]. The main residues in the totally refined oil were only identified as V and VI compounds (Table 4). While the chromatographic analysis of methanol revealed the presence of $\mathrm{V}$ and VI as free metabolites beside the hydrophilic compounds in addition to conjugated metabolites which upon acid hydrolysis were identified as VI and VII, VIII compounds (Fig. 2). The formation of these products indicates that fenitrothion is degraded via oxidation of $\mathrm{P}=\mathrm{S}$ to $\mathrm{P}=\mathrm{O}$ to yield oxon analogue [II], cleavage of the P-O-alkyl to yield desmethyl compound [III] and hydrolysis to yield its phenol [IV]. While, pirimiphos-methyl is degraded via hydrolysis to give [VI] in addition to cleavage of the N-alkyl groups to give VII and VIII.

Egypt. J. Chem. 53, No. 6 (2010) 
TABLE 4. $R_{f}, R_{t}$ values and percent of pirimiphos-methyl and its degradation products in maize oil after subjecting to different commercial processing procedures.

\begin{tabular}{|c|c|c|c|c|c|c|c|c|c|}
\hline \multirow[b]{2}{*}{ Compound } & \multicolumn{3}{|c|}{$\mathbf{R}_{\mathrm{f}}$ values } & \multirow{2}{*}{$\begin{array}{c}\mathbf{R}_{\mathrm{t}} \\
\text { values }\end{array}$} & \multicolumn{5}{|c|}{ Relative percentage \% } \\
\hline & Sys. 1 & Sys. 2 & Sys. 3 & & $\mathbf{A}$ & $\mathbf{B}$ & $\mathbf{C}$ & D & $\mathbf{E}$ \\
\hline $\begin{array}{l}\text { Pirimiphos-methyl } \\
\text { [V] }\end{array}$ & 0.95 & 0.96 & 0.90 & 6.96 & 65 & 45 & 34 & 28 & 10 \\
\hline $\begin{array}{l}\text { 2-Diethylamino-4- } \\
\text { hydroxy-6- } \\
\text { methylpyrimidine } \\
{[\mathrm{VI}]}\end{array}$ & 0.80 & 0.72 & 0.12 & 6.58 & 20 & 35 & 40 & 45 & 54 \\
\hline $\begin{array}{l}\text { 2-Ethylamino-4- } \\
\text { hydroxy-6- } \\
\text { methylpyrimidine } \\
\text { [VII] }\end{array}$ & 0.61 & 0.45 & 0.0 & & 5 & 4 & 2 & Trace & - \\
\hline $\begin{array}{l}\text { 2-Amino-4-hydroxy- } \\
\text { 6-methylpyrimidine } \\
\text { [VIII] }\end{array}$ & 0.30 & 0.21 & 0.0 & & 5 & 3 & 2 & Trace & -- \\
\hline
\end{tabular}

$\mathrm{A}=$ Crude oil, $\mathrm{B}=$ Alkali refined oil, $\mathrm{C}=\mathrm{Bleached}$ oil, $\mathrm{D}=$ Winterized oil, $\mathrm{E}=$ Deodorized oil System 1= Chloroform: Methanol (17:3)

System 2= Diethyl ether: Hexane: Methanol: Ammonia (16:4:4:1)

System 3= Cyclohexane: Ethylacetate $(1: 1)$

It is worthy to mention that, the removal efficiency during the refining processes seems to depend upon the nature of residues present. Data obtained emphasize the importance of studying the effect of oil refinement on reduction and/or elimination of aged pesticide residues in edible oils.

\section{Bioavailability to rats}

Elimination and distribution of ${ }^{14} \mathrm{C}$-fenitrothion and/or ${ }^{14} \mathrm{C}$-pirimiphosmethyl, after feeding rats with the extracted maize seeds (cake) for three days are shown in Table 5. In case of ${ }^{14} \mathrm{C}$-fenitrothion, the major portion of radioactivity was eliminated via expired air (50\%), feces (10\%) and urine (5\%). Appreciable amount of ${ }^{14} \mathrm{C}$-residues were also detected in liver, kidney, blood, fat and heart $(22 \%)$.

TABLE 5. Elimination and distribution of bound ${ }^{14} \mathrm{C}$-fenitrothion and ${ }^{14} \mathrm{C}$-pirimiphosmethyl residues on extracted maize seeds (cake) fed to rats for three days.

\begin{tabular}{|c|c|c|c|c|}
\hline \multirow[b]{2}{*}{ Sample } & \multicolumn{2}{|c|}{${ }^{14} \mathrm{C}$-fenitrothion } & \multicolumn{2}{|c|}{${ }^{14} \mathrm{C}$-pirimiphos-methyl } \\
\hline & $\begin{array}{c}\text { Insecticide }^{(1)} \\
\text { equivalent }^{(1)} \\
(\mu \mathrm{g})\end{array}$ & $\begin{array}{c}\text { Percentage of } \\
\text { administrated } \\
\text { dose }(\%)\end{array}$ & $\begin{array}{c}\begin{array}{c}\text { Insecticide } \\
\text { equivalent }^{(2)} \\
(\mu \mathrm{g})\end{array} \\
\end{array}$ & $\begin{array}{c}\text { Percentage of } \\
\text { administrated } \\
\text { dose }(\%)\end{array}$ \\
\hline Carbon dioxide & $42.0 \pm 1.30$ & 50 & $1.50 \pm 0.26$ & 7 \\
\hline Urine & $4.5 \pm 0.26$ & 5 & $9.90 \pm 0.04$ & 47 \\
\hline Feces & $8.5 \pm 0.20$ & 10 & $2.50 \pm 0.30$ & 12 \\
\hline Blood & $6.7 \pm 0.20$ & 8 & $2.00 \pm 0.20$ & 9.5 \\
\hline Liver & $5.0 \pm 0.36$ & 6 & $1.25 \pm 0.03$ & 6 \\
\hline Fat & $4.0 \pm 0.26$ & 5 & $0.55 \pm 0.15$ & 2.5 \\
\hline Kidney & $1.7 \pm 0.15$ & 2 & $0.95 \pm 0.02$ & 4.5 \\
\hline Heart & $0.9 \pm 0.05$ & 1 & $0.85 \pm 0.04$ & 4 \\
\hline Recovery & 73.3 & 87 & 19.5 & 92.5 \\
\hline
\end{tabular}

(1) Administrated dose $=100 \%$ (84 $\mu$ g equivalent/rat).

(2) Administrated dose $=100 \%$ (21 $\mu$ g equivalent $/$ rat $)$. Data are means of three replicates. 
In case of ${ }^{14} \mathrm{C}$-pirimiphos-methyl, the total excretion represented about $66 \%$ of the originally consumed dose. The main excretion route was the urine $(47 \%)$ while the radioactivity in expired air and feces represented $7 \%$ and $12 \%$, respectively. About $26 \%$ of the administrated radioactivity was detected among various organs of the rat. This indicates that the main routes of elimination are via respiration and urine for fenitrothion and pirimiphos-methyl, respectively.

The highest percent was observed in blood $8-9.5 \%$, for both insecticides as shown in Table 5. The total recovery of ${ }^{14} \mathrm{C}$-activity amounted to $87 \%$ and $92.5 \%$ of the administrated dose for fenitrothion and pirimiphos-methyl, respectively. This indicates a high percentage of release of bound residues followed by distribution of these residues or their degradation products among tissues of experimental animals.

In case of fenitrothion, chromatographic analysis of urine showed the presence of the hydrophilic compounds only in free and conjugated form. This result agrees with some previous reports ${ }^{(35-37)}$ which noted that, in adult rats, the insecticide is metabolized to phosphorothioate and dimethylphosphate compounds. While compound VI represented the main substance in collected urine in free and conjugated form besidetraces of compounds VII and VIII in case of pirimiphos-methyl. These findings are in accordance with other recent studies $^{(38)}$.

Bound ${ }^{14} \mathrm{C}$-fenitrothion and ${ }^{14} \mathrm{C}$-pirimiphos-methyl in maize seeds proved to be highly bioavailable to rats. The data obtained are in line with many recent studies which indicate a moderate to high bioavailability of soybean bound residues of pirimiphos-methyl ${ }^{(38)}$, chlorpyrifos $^{(39)}$, dichlorovos ${ }^{(40)}$, fenitrothion ${ }^{(41)}$ and canola bound residues of prothiofos ${ }^{(33)}$.

\section{Conclusion}

Refining processes led to progressive degradation of fenitrothion and pirimiphos-methyl insecticides. Their residues in maize seed oil included the parent compound beside both free and conjugated metabolites. About 81-87\% of the ${ }^{14} \mathrm{C}$-activity in the crude maize seed oil could be eliminated by stimulated commercial processes locally used for oil refining. The deodorization was found to be an efficient step for reduction of the insecticide residues. Neutralization and bleaching processes led to significant losses of the pesticide residues in oil as well. The removal efficiency during the refining processes seems to depend upon the nature of the residues present. The data obtained emphasize the importance of studying the effect of oil refinement on the reduction and/or elimination of aged pesticides residues in edible oils.

The present results indicate that maize-bound fenitrothion or pirimiphosmethyl residues are highly bioavailable to rats fed with the extracted seeds. The total recovery of ${ }^{14} \mathrm{C}$-activity of insecticides amounted to $87-93 \%$ of the administrated dose. The main excretion routes are via expired air and urine and

Egypt. J. Chem. 53, No. 6 (2010) 
small amounts of the radioactivity were distributed among various organs of experimental animals. Therefore, it should be stressed that the presence of bound pesticide residues can no longer be ignored in the evaluation of toxicological hazards.

\section{References}

1. Kaushik, G., Satya, S. and Naik, S.N., Food processing a tool to pesticide residue dissipation: A review. Food Research International, 42, 26-40 (2009).

2. Zayed, S. M. A. D., Farghaly, M. and Mahdy, F., Lindane degradation and effects on soil microbial activity. Food Chemistry, 62, 265-268 (1998).

3. Hibert, G., Lillemark, L., Balchen, S. and Schriver-Hojskov C., Reduction of organochlorine contaminants from fish oil during refining. Chemosphere, 37, 12411252 (1998).

4. Fukazawa, T., Aoyama, M.; Tsutsumi, T., Tokairin, S., Ehara, H., Maruyama, T. and Niiya, I., Behavior of pyrethroid pesticides toward edible oils during refining. $J$. The Japan Oil Chemical Society, 48, 885-889 (1999a)

5. Fukazawa, T., Tsutsumi, T., Tokairin, S., Ehara, H., Maruyama, T. and Niiya, I., Behavior of organophosphorus pesticides obtained from oils by refining treatment. $J$. The Japan Oil Chemical Society, 48, 247-251 (1999b)

6. Mahdy, F. and El-Magraby, S., Effect of processing on ${ }^{14} \mathrm{C}-\mathrm{Chlorfenvinphos}$ residues in maize oil and bioavailability of its cake residues on rats. Bull. Environ.Contam. Toxicol. 84, 582-586 (2010).

7. Egyptian Ministry of Agriculture Technical Recommendation for Agricultural Pests Control p. 65 (2007).

8. Hassall, K.A. The Biochemistry and Uses of Pesticides; Structure, Metabolism, Mode of Action and Uses in Crop Protection. $2^{\text {nd }}$ edition VCH. Publishers, NY. (1990).

9. Briggs, S.A., Bassic Guide to Pesticides; Their Characteristics and Hazards. Hemisphere Publishing Crop., Washington, Philadelphia, London (1992).

10. Meaklin, J., Yang, J., Drummer, O.H., Killalea, S., Staikos, V., Horomidis, S., Rutherford, D., Demos, L.L., Lim, S., Mchean, A.J. and McNeil, J.J., Environ. Health Perspect. 111, 305-308 (2002).

11. Uygun, U., Koksel, H. and Atli, A., Residue levels of malathion and its metabolites and fenitrothion in post-harvest treatment wheat during storage, milling and baking. Food Chem. 92, 643-647 (2005)

12. Tomlin, C.D.S. (Ed). The Pesticide Manual: A World Compendium, $11^{\text {th }}$ ed, The British Crop Protection Council, Surrey, UK, p.514 (1997). 
13.Tigar, B.J. and Pinner, D.B., A comparison of the toxicity of pirimiphos-methyl and malathion to Typhaea stercorea (L.) when applied to stored maize. J. Stored Prod. Res. 32, 307-313 (1996).

14. Eto, M., Organophosphorus Pesticides: Organic and Biological Chemistry, CRC, Press, INC Florida 249 (1979).

15. Mattews, K.P. and Maliphant, P., Pesticide Science, 37, 93-97 (1993).

16. Ghaly, A.E., Alkoaik, F. and Snow, A., Degradation of pirimiphos-methyl during thermophilic composting of greenhouse tomato plant residues. Canadian Biosystems Engineering, 9, 1-11 (2007)

17. Petar Lj. Jovanović, Ljubica, P. Dokić and Branimir, J. Maric, Fatty acid composition of maize germ oil from high-oil hibrids wet-milling processing. Apteff, 36, 1-266 (2005)

18. Feng, F., Myers, D. J., Hojilla-Evangelista, M. P., Miller, K. A., Johnson, L. A. and Singh, S. K., Quality of corn oil obtained by sequential extraction processing. Cereal Chem. 79, 707-709 (2002).

19. Farghaly, M., Mahdy, F., Taha, H. and Fathy, U., Behavior of the organophosphorus insecticide fenitrothion in stored faba beans and its biological effects towards experimental animals. Journal of Environmental Science and Health, Part B 42, 655662 (2007).

20. Akintonwa, D.A.A. and Hutson, D.H., Metabolism of 2-chloro-1-(2,4,5trichlorophenyl)vinyl dimethyl phosphate in the dog and rat. J. Agric. Food Chem. 15, 632-637 (1967).

21. Akhtar, M.H. and Foster, T.S., Metabolism of tetrachlorvinphos by the soluble fraction $(105,000 \mathrm{~g})$ from chicken liver homogenates. J .Agric. Food Chem. 25, $1017-$ 1022 (1977).

22. Young, K., Sung, L.H., Chae, P.Y. and Tae, L.Y., A convenient method for oxidation of organophosphorus pesticides in organic solvents. Environ. Research A, 84, 303-309 (2000).

23. Macko, J.I., Zakova, L. and Kopinic, V., An improved method for preparation of O,O- diethyl O - [ 2 -(diethylamino) - 6 - methyl-4-pyrimidinyl] phosphorothioate (pirimiphos-methyl). Czech. Cs. 264, 735 (Cl. AO/N37/16) 15 Dec. (1989) Appl. 87/6,923,28 Sep. (1987). 4 pp. C.A., 114, 164508 (1991).

24. Iwakura, Y., Nagakubo, K. and Hosogan, C., Preparation of ketene dimer and synthesis of pyrimidine derivatives by use of ketene dimer. J. Chem. Soc. Japan, 57, 947-949 (1954).

25. Kline, S. and French Laboratories by David H. Tedschi Belg. 657, 135, June 15, (1965) U.S. Appl. Dec. 26, 13 pp (1963). 
26. Yuen, S.H., Traviolet spectrophotometric and thin-layer chromatographic determination of pirimiphos-ethyl and pirimiphos-methyl in insecticide formulations. Analyst, 101, 533-539 (1976).

27. Zayed, S. M. A. D.; Farghaly, M. and Mahdy, F., Effects of refining processes on magnitude and nature of malathion and carbofuran residues in cotton seed oil. Arab. J. Nuclear Sci. and Applications, 38, 277-283 (2005).

28. L'Annunziata, M.F., Radiotracers in Agricultural Chemistry, IAEA, Academic Press, London, NY, San Francisco, 89-145 (1979).

29. Bhatnagar, A. and Gupta, A., Chlorpyriphos, quinalphos, and lindane residues in sesame seed and oil (Sesamum indicum L.). Bull. Environ. Contam. Toxicol. 60, 596-600 (1998).

30. Zayed, S.M.A.D., Farghaly, M. and Mahdy, F., Efficiency of the refining processes in removing ${ }^{14} \mathrm{C}$-Pirimiphos- methyl residues in soybeans oil .Bull. NRC, Egypt, 28, 567-575 (2003).

31. Miyahara, M. and Saito, Y, Pesticide removal efficiencies of soybean oil refining processes. J Agric Food Chem. 41, 731-734 (1993).

32. Mendez, M.V.R., De La Rosa, I.P., Marquez, A. J. and Ojeda, M.U., Elimination of pesticides in olive oil by refining using bleaching and deodorization. Food Additives and Contaminants, 22, 23-30 (2005).

33. Abdel-Gawad, H. and Hegazi, B., Fate of ${ }^{14} \mathrm{C}$-ethyl prothiofos insecticide in canola seeds and oils. Journal of Environmental Science and Health Part B, 45, 116-120 (2010).

34. Hegazi, B.; Abdel-Gawad, H. and Afifi, L.M., ${ }^{14}$ C-Zineb residues in sunflower seeds and oils and the effect of processing. Arab J. Nucl. Sci. Appl. 36, 345-354 (2003).

35. Levi, P.E, Hollingworth, R.M. and Hodgson, E., Differences in oxidative dearylation and desulfuration of fenitrothion by cytochrome P-450 isoenzymes and in the subsequent inhibition of monooxygrnase activity. Pestic. Biochemistry and Physiology, 32, 224-231 (1988).

36. Kumar, R., Roy, S., Rishi, R. and Sharma, C.B., Metabolic fate of fenitrothion in liver, kidney and brain of rat. Biomedical Chromatography, 7, 301-305 (1993).

37. Sultatos, L.G., Mammalian toxicology of organophosphorus pesticides. Journal of Toxicology and Environmental Health, 43,271-289 (1994).

38. Mahdy, F., Bioavailability to rat and toxicity of bound pirimiphos-methyl residues in stored Soybeans . Bull. NRC, 28, 403-413 (2003).

39. El-Maghraby, S., Bioavailability and toxicological potentional to rats of bound ${ }^{14} \mathrm{C}$-Chlorpyrifos residues in soybeans. Bull. NRC, Egypt, 25, 259-268 (2000). 
40. Mahdy, F. and taha, H., toxicity of bound ${ }^{14} \mathrm{C}$-dichlorvos residues in stored soybeans and their bioavailability to rat. Bull. NRC. 32, 125-137 (2007).

41. Farghaly, M. and El-Maghraby, S., Toxicological evaluation and bioavailability of ${ }^{14} \mathrm{C}$-fenitrothion bound residues on soybeans towards experimental animals. Food and Chemical Toxicology, 46, 3111-3115 (2008).

(Received 22/12/2010 ; accepted 25/2/2011)

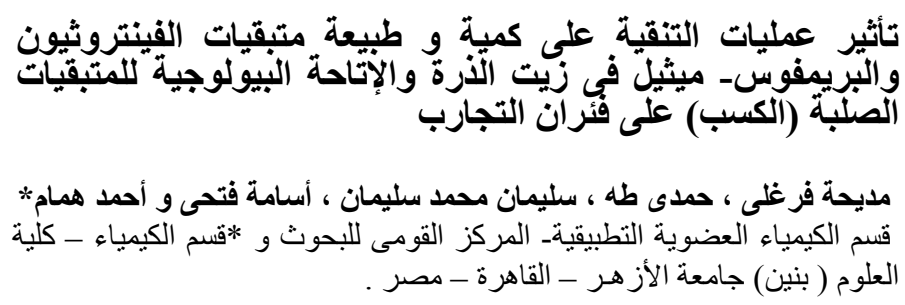

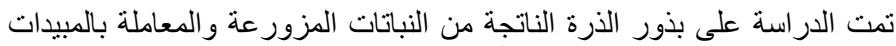

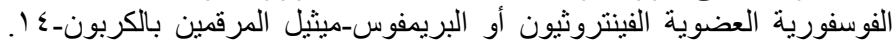

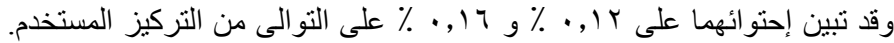

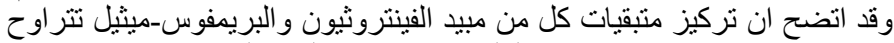

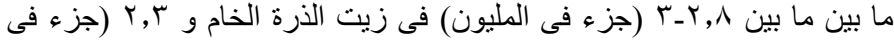

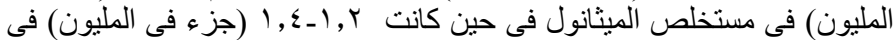
الكسب (المتبقيات المتحدة بالحبوب) على التى فئ التى الى

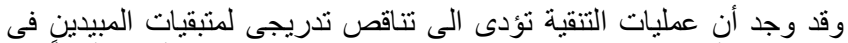

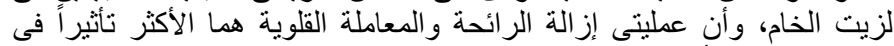

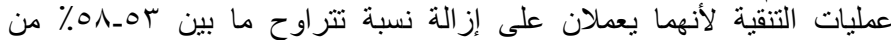

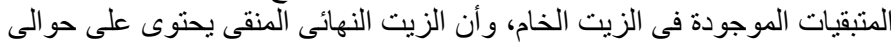

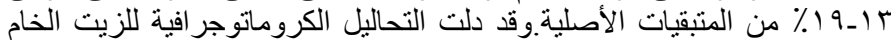

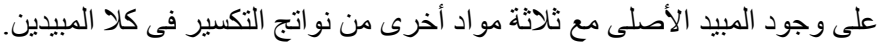

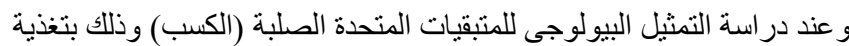

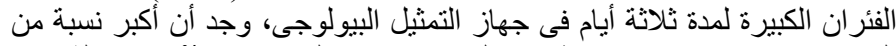

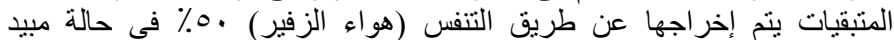

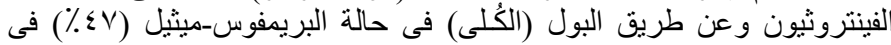

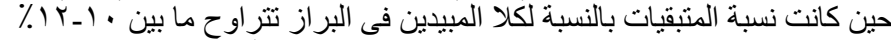

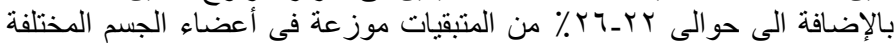

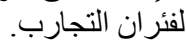

Egypt. J. Chem. 53, No. 6 (2010) 